\title{
Pistas lexicais e sintáticas para a delimitação de adjetivos na aquisição do Português Brasileiro
}

Luciana Teixeira (UFJF)

Recebido 17 fev. 2011 / Aprovado 7, mar. 2011

\section{Resumo}

Este artigo apresenta um estudo experimental cujo foco é a delimitação da categoria adjetivo por crianças adquirindo o Português Brasileiro (PB) como língua materna. Adota-se uma perspectiva psicolinguística de aquisição da linguagem, aliada a uma concepção minimalista de língua (CHOMSKY, 1995-2001). Assume-se que a criança é sensível às propriedades fônicas de elementos de classes fechadas, como determinantese afixos, conforme a hipótese do bootstrapping fonológico (MORGAN \& DEMUTH, 1996; CHRISTOPHE et al., 1997). Com base na hipótese do bootstrapping sintático (GLEITMAN, 1990), assume-se que a análise de adjetivos no contexto sintático de DPs ou de small clauses, aliada ao pressuposto de que DPs fazem referência a objetos/ entidades, possibilita a representação de adjetivos como categoria que apresenta uma propriedade ou atribu to de um referente. Avalia-se, ainda, o papel da ordem canônica, na distinção entre adjetivos e nomes. Apresentam-se dois experimentos com crianças, usando-se a técnica de seleção de objetos com pseudopalavras: o primeiro foi conduzido com crianças de 18-22 meses; o segundo, com crianças de 2-3 anos e 4-5 anos. Os resultados dos experimentos aqui relatados são compatíveis com a hipótese de que a criança faz uso de informação sintática e morfológica na delimitação de adjetivos, e revelam que já aos dois anos de idade propriedades semânticas de sufixos formadores de adjetivos são representadas pela criança.

Palavras-chave: aquisição da linguagem; adjetivo; bootstrapping; categorias funcionais; afixos derivacionais 


\section{Introdução}

Estudos em aquisição da linguagem vinculados à teoria linguística têm sido conduzidos, de maneira geral, independentemente daqueles voltados para os procedimentos de aquisição. Neste caso, a formulação do problema da aquisição da linguagem não abarca $o$ modo como a criança identifica as propriedades da língua presentes no fluxo da fala à sua volta. Por outro lado, notase, em muitos estudos sobre aquisição da linguagem, a ausência de um modelo teórico de língua que explicite o que deve ser adquirido pela criança e o que pode ser atribuído a um programa biológico.

Buscando caracterizar o tipo de informação que poderia alavancar o processo de aquisição, e considerando que toda informação gramaticalmente relevante para a criança tem de ser legível nas interfaces do sistema da língua com sistemas de desempenho, a perspectiva teórica assumida neste trabalho é a de se considerar, de forma integrada, uma teoria linguística que contemple o problema da aquisição da linguagem - particularmente a teoria de Princípios e Parâmetros, nos termos do Programa Minimalista (CHOMSKY, 1995; 1999 e obras posteriores) - e abordagens psicolinguísticas que considerem, como meios de desencadear a aquisição de uma língua: (i) o tratamento do sinal acústico da fala (bootstrapping fonológico: MORGAN \& DEMUTH, 1996; CHRISTOPHE et al., 1997); (ii) a análise do material linguístico pela criança na aquisição de significado lexical (bootstrapping sintático: GLEITMAN, 1990), como proposto em Corrêa (2006).

Uma das tarefas que se apresentam à criança na aquisição de sua língua materna é a de descobrir de que maneira propriedades ou atributos são apresentados lexicalmente na língua: se por elementos de uma categoria lexical (como a dos adjetivos), como na maior parte das línguas conhecidas, se por meio de morfemas livres ou presos, como em Haússa (língua afro-asiática falada na Nigéria), ou no Chinês (Cf. ROSA, 2000). Além disso, no que concerne à sintaxe da língua, a criança deverá fixar o valor de parâmetros de ordem que determinam a posição do adjetivo no DP.

Seguindo essa perspectiva, o problema de como se dá o desencadeamento da aquisição da categoria adjetivo (em qualquer língua na qual ele se realize como elemento de classe aberta ou de classe fechada, sob a forma de afixos) pode ser formulado em termos de um processo que compreende: (i) a segmentação, pela criança, do input linguístico que lhe é oferecido; (ii) o estabelecimento de uma relação entre aquilo que se mostra acessível à criança em termos de padrões regulares que se apresentam na interface fônica e o que se constitui como informação acessível ao sistema computacional, responsável pelo tratamento linguístico dessa informação; (iii) a capacidade por parte da criança de tomar 
o produto do processamento do sinal da fala como interface fônica para a sintaxe da língua, vinculando a esta uma interface de natureza semântica/intencional (Cf. CORRÊA , 2006). Tal assunção é relevante no que se refere à identificação de propriedades de traços formais ${ }^{1}$ (entre os quais se encontram $\mathrm{Ne} \mathrm{V}$ ), uma vez que sobre eles opera o sistema computacional na aquisição do léxico.

Mais especificamente, no caso da aquisição de adjetivos em línguas como o PB, pela hipótese do bootstrapping fonológico, pressupõe-se que a criança seja sensível às propriedades fônicas de elementos de classes fechadas, como determinantes e afixos (dentre os quais se destacam os sufixos derivacionais). A representação da categoria funcional D, nos termos da teoria linguística (ainda que subespecificada), é tida como necessária para que a

Pela proposta minimalista, a distinção formal entre nome e adjetivo resulta, respectivamente, da combinação [+N, -V], [+N, +V], no que pode ser assumido como traços categoriais, quando do mapeamento de enunciados linguísticos a objetos/entidades e a propriedades, respectivamente (Cf. CHOMSKY, 1995). Em sentido estrito, a identificação da gramática é vista como identificação das propriedades dos traços formais de categorias funcionais. No entanto, uma vez que o adjetivo pode ser realizado de diferentes formas na morfologia das línguas, considera-se que sua delimitação também seja crucial à identificação de uma gramática.

2 Do ponto de vista da teoria linguística, os elementos do léxico distinguem-se em duas grandes categorias: lexicais e funcionais. Das categorias lexicais fazem parte elementos das denominadas "classes abertas" (como Nomes, Adjetivos, Verbos); já as categorias funcionais caracterizam-se como sendo classes fechadas, de que fazem parte Determinantes (D), Tempo (verbal) (I), Complementizador (C), importantes para referência a entidades, situação do evento e força ilocucionária, respectivamente. Para mais informações a respeito dessa distinção, ver Chomsky (1995). criança venha a identificar o Nome enquanto categoria lexical e, a partir deste, o Adjetivo. Considera-se, ainda, que o DP possa ser tomado como expressão referencial pela criança para a definição das propriedades semânticas do adjetivo no uso da língua, no que diz respeito à referência específica ou avaliativa. Pela hipótese do bootstrapping sintático, assume-se que a criança, por meio da análise sintática a qual já é apta a conduzir, seja capaz de perceber que o traço categorial que define adjetivos diz respeito à atribuição de propriedades a entidades e eventos, dado o pressuposto de que enunciados linguísticos se referem a estes. Considera-se que, com base nessa análise, uma dada forma gramatical seria identificada pela criança como adjetivo, quando do processamento de enunciados linguísticos que incluam essa categoria lexical como adjuntos e/ou predicativos.

Portanto, questões relativas à ordenação linear de constituintes e morfemas e à identificação no input de elementos funcionais $^{2}$ e afixos (neste caso, os sufixos derivacionais formadores de adjetivos) são exploradas neste estudo, enquanto informação que a criança leva em conta na aquisição de adjetivos. No que concerne aos afixos derivacionais semanticamente não-vazios (como -oso e -ento), verifica-se seu papel na atribuição do traço categorial ao adjetivo, assim como o modo pelo qual crianças os interpretam. Assim, do ponto de vista da aquisição de adjetivos no $\mathrm{PB}$, a criança deverá captar o fato de que os adjetivos admitem diferentes posições no enunciado em função da estrutura sintática em que se inserem. Ela deverá ser capaz também de perceber que a interpretação do adjetivo é dependente do processamento da relação sintática estabelecida com o nome e da representação conceptual de atributos.

\section{Aquisição de nomes e adjetivos}

Pesquisas em aquisição da linguagem vêm investigando o modo como categorias lexicais são delimitadas. Estudos conduzidos com crianças adquirindo o inglês (WAXMAN, 1999) sugerem que, aos 13 meses, a criança é capaz de relacionar uma nova 
palavra a uma determinada categoria (Nome, Adjetivo) em função do modo como essa palavra lhe é apresentada (com propriedades morfofonológicas distintas). Em experimentos posteriores, Waxman \& Booth (2001) obtiveram resultados ainda mais expressivos, compatíveis com a hipótese de que a apresentação de objetos por nomeação (This is a blicket) ou por meio de uma construção com adjetivo (This one is blickish) guia a atenção da criança para a identificação de categoria (nome) ou de propriedade (adjetivo). A relevância da percepção de informação morfológica relativa a afixos derivacionais (como em "blickish"), para a delimitação de nomes versus adjetivos, se explica pela especificidade dessas formas presas no que diz respeito à distinção de categorias lexicais.

Em outro estudo conduzido com crianças adquirindo o inglês, Mintz \& Gleitman (2002) encontraram resultados convergentes com a hipótese de que as crianças estendem sistematicamente os adjetivos a propriedades de objetos. Foram realizados experimentos em que novos adjetivos foram apresentados precedendo um nome (the stoof horse), pronome (the stoof one) ou "nome genérico" (the stoof thing). Crianças de 24 a 36 meses revelaram mais facilidade em mapear um novo adjetivo como propriedade de um objeto na condição nome, o que sugere ser necessária a identificação desta categoria para a atribuição de propriedade ao objeto, quando não há informação proveniente de afixos derivacionais relativos a adjetivos. Desse modo, o estabelecimento de um vínculo entre a forma gramatical adjetivo e seu significado representa uma etapa subsequente no desenvolvimento, construída a partir da relação nome/categoria de objeto, sendo modelada pelas propriedades semânticas e sintáticas dos adjetivos na língua em aquisição.

Com base nas evidências experimentais relatadas, temos que, de um lado, a marca morfofonológica característica de adjetivo (-ish, em inglês) parece facilitar a identificação de elementos dessa categoria (cf. resultados de WAXMAN \& BOOTH, 2001); por outro lado, a presença do nome modificado pelo adjetivo parece ser requerida quando este não apresenta marca morfofonológica (Cf. resultados de MINTZ \& GLEITMAN, 2002), indicando sensibilidade da criança a informação de natureza distribucional; portanto, à ordem dos elementos da língua em aquisição.

No que se refere à identificação de nomes e adjetivos no processo de aquisição do Português Brasileiro (PB), os estudos são ainda incipientes. Evidências experimentais de uma pesquisa inicial realizada por Name (2005) e, na sequência, por Almeida (2007) com crianças brasileiras em torno dos três anos de idade apontam para o uso de informação referente à ordem estrutural de constituintes como forma de identificação de nomes e adjetivos desconhecidos. 
Em Almeida (2007), as crianças, divididas em dois grupos em função da faixa etária (Grupo A - crianças abaixo de 3 anos; Grupo B - crianças acima de 3 anos) participaram de uma tarefa de seleção de imagens de objetos inventados, com propriedades desconhecidas (formas inventadas, por ex.). A apresentação das imagens foi feita por meio de pseudopalavras ("Olha quantos mabos bipos!"), de modo a nomear a categoria (pseudonome) e uma propriedade da categoria (pseudoadjetivo). De acordo com os resultados, as crianças abaixo de 3 anos (Grupo A) identificaram a primeira pseudopalavra do DP como categoria, e a segunda, como propriedade, sugerindo que a posição estrutural canônica do português referente a nomes e adjetivos (Determinante + Nome + Adjetivo) parece guiar o mapeamento das pseudopalavras. Por outro lado, os resultados referentes ao Grupo B sinalizam que crianças acima de 3 anos mapeiam, com frequência maior do que as mais novas, a primeira pseudopalavra como propriedade, e a segunda como categoria, sugerindo que a identificação de elementos em ordem não-característica do português (Determinante + Adjetivo + Nome) toma a ordenação canônica como referência para a anteposição do adjetivo.

Neste artigo, reportam-se os resultados de dois experimentos conduzidos com crianças adquirindo o PB, em que se busca investigar a sensibilidade de crianças entre 18 e 22 meses à informação de natureza morfológica proveniente de afixos derivacionais, aliada à informação sintática no que diz respeito à

${ }^{3}$ Para a formação dos pseudoadjetivos, empregados nas sentenças durante a realização das tarefas experimentais, foram escolhidos os sufixos -oso e -ento a partir da aplicação dos Inventários MacArthur (questionários de compreensão e produção de vocabulário). Neste trabalho, foi utilizada apenas a parte referente a "Qualidades e Atributos" do protocolo Palavras e Sentenças (para crianças de 16 a 30 meses), tendo em vista o tema focalizado neste estudo e a idade média das crianças participantes dos dois experimentos. Para o preenchimento da referida seção do questionário, contou-se com a colaboração dos pais das crianças, residentes na cidade de Juiz de Fora, onde se realizaram as tarefas experimentais. Para um estudo mais detalhado a respeito dos Inventários MacArthur, ver Teixeira (2000). posição do adjetivo adjunto, modificador do nome (à direita ou à esquerda). Por ex., "Este é um dabo miposo" ou "Este é um miposo dabo". Investiga-se, ainda, se crianças de duas faixas etárias (2-3 anos e 4-5 anos) interpretam os afixos -oso e -ento ${ }^{3}$ de pseudoadjetivos na interface semântica.

\section{Experimentos}

\subsection{Experimento 1 - Sensibilidade à posição estrutural do adjetivo adjunto e a afixos derivacionais}

\section{Objetivos:}

(i) verificar se crianças de 18-22 meses adquirindo o PB são sensíveis à ordem canônica NP + Adjetivo no DP, ao inferir a classe e o significado de palavras novas a partir de pseudopalavras;

(ii) aferir o peso relativo da informação concernente à ordem nome/adjetivo e adjetivo/nome diante da informação proveniente de afixos derivacionais (por sua especificidade no que diz respeito à distinção de categorias lexicais). 
Variáveis independentes (compondo um design 2 X 2):

a) posição estrutural (adjetivo à direita/à esquerda do nome);

b) presença de afixo derivacional (presença ou ausência) $\rightarrow$-oso/-ento

Variável dependente: o número de escolhas referentes ao novo objeto inventado com a propriedade-alvo. Por exemplo: objeto com bolinhas roxas, ou triângulos verdes, ou quadrados laranja, ou cruzes vermelhas (ver Fig. 1 adiante).

\section{Condições experimentais:}

\section{Condição 1 - Adjetivo à direita do Nome (Det + N + Adj)} / Com Afixo

- Familiarização: Este é um dabo miposo. Este aqui também é um dabo miposo. Este outro aqui é um dabo miposo também.

- Contraste: Ih! Este não é um dabo miposo. Este aqui também não é um dabo miposo. Este outro aqui também não é um dabo miposo.

- Teste: Pega o (que é) miposo pra mim.

Condição 2- Adjetivo à direita do Nome (Det + N + Adj) / Sem Afixo

- Familiarização: Este é um dabo mipe. Este aqui também é um dabo mipe. Este outro aqui é um dabo mipe também.

- Contraste: Ih! Este não é um dabo mipe. Este aqui também não é um dabo mipe. Este outro aqui também não é um dabo mipe.

- Teste: Pega o (que é) mipe pra mim.

Condição 3- Adjetivo à esquerda do Nome (Det + Adj + Nome) / Com Afixo

- Familiarização: Este é um miposo dabo. Este aqui também é um miposo dabo. Este outro é um miposo dabo também.

- Contraste: Ih! Este não é um miposo dabo. Este aqui também não é um miposo dabo. Este outro também não é um miposo dabo.

- Teste: Pega o (que é) miposo pra mim. 
Condição 4- Adjetivo à esquerda do Nome (Det + Adj + Nome) / Sem Afixo

- Familiarização: Este é um mipe dabo. Este aqui também é um mipe dabo. Este outro é um mipe dabo também.

- Contraste: Ih! Este não é um mipe dabo. Este aqui também não é um mipe dabo. Este outro também não é um mipe dabo.

- Teste: Pega o (que é) mipe pra mim.

\section{Hipótese:}

A criança é sensível à informação relativa à ordem linear com que unidades do léxico se apresentam e informação pertinente a elementos de classes fechadas, como afixos derivacionais, importantes na distinção de categorias lexicais.

\section{Método:}

Participantes: 16 crianças, com idade média de 20 meses (7 do sexo feminino; 9 do sexo masculino), de uma creche-escola de Juiz de Fora participaram do experimento. Todas elas foram testadas individualmente, com a presença da professora ou ajudante de confiança. As crianças foram submetidas a 2 trials de cada condição experimental, de modo que, ao fim da tarefa, cada criança realizou 8 testes. Os resultados foram anotados para análise posterior.

Material: Para a realização das tarefas, utilizaram-se 32 objetos manufaturados (Fig. 1 abaixo), selecionados de modo a formar 4 grupos diferentes de 9 objetos cada (para se ter um exemplo, ver quadro 1 adiante). Em cada condição experimental, durante a fase de familiarização, as crianças viram 3 objetos inventados iguais na forma, com cores diferentes e com a mesma propriedade (ex. bolinhas roxas ou triângulos verdes ou quadrados laranja). Na etapa do contraste, cada criança viu: 2 objetos conhecidos da criança (ex. banana e bola ou lua e flor); 1 objeto inventado semelhante ao da familiarização, sem a propriedade-alvo e 1 objeto inventado diferente ao da familiarização, sem a propriedade-alvo. Na fase teste, foi apresentado um par de objetos inventados: 1 igual ao da familiarização, de outra cor e com uma nova propriedade (ex. cruzes vermelhas) e 1 igual ao do contraste, de outra cor e com a propriedade-alvo (ex. bolinhas roxas). 
Objetos conhecidos

Objetos inventados
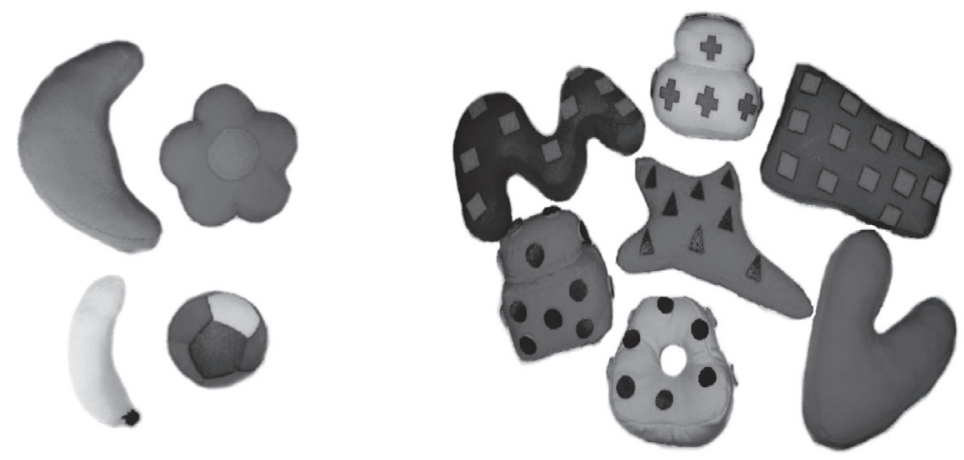

Fig. 1 - Objetos manufaturados

\section{Previsões:}

(a) Espera-se um efeito principal da presença de afixo, com mais respostas concernentes à propriedade dos objetos, caso a criança reconheça os sufixos derivacionais;

(b) espera-se, ainda, um possível efeito principal da posição estrutural, com mais respostas relativas à propriedade dos objetos, se a criança identificar a primeira pseudopalavra apresentada como Nome, e a segunda, como Adjetivo, mapeando o objeto ou a propriedade do objeto.

\section{Procedimento:}

Foi usado o paradigma da seleção de objetos em situação de aprendizagem de palavras novas/conceitos novos, segundo o qual a criança teve como tarefa mostrar à pesquisadora o que foi pedido, a partir de objetos manufaturados. Os brinquedos foram inventados a fim de evitar qualquer interferência decorrente de conhecimento prévio da criança, quando do mapeamento entre a pseudopalavra e o objeto inventado ou entre a pseudopalavra e a propriedade do objeto inventado. Após chegar à creche-escola, a experimentadora iniciou a familiarização com a tarefa de manipulação de brinquedos, a partir de objetos conhecidos, apresentando-os aos pares e nomeando-os: carrinho barulhento/silencioso. Em seguida, teve início a apresentação dos objetos inventados. $\mathrm{O}$ procedimento incluiu três fases distintas: familiarização, contraste e teste (Cf. apresentado nas Condições Experimentais). Para se ter um exemplo, ver quadro 1 abaixo: 


\begin{tabular}{|c|c|c|}
\hline FAMILIARIZAÇÃO & CONTRASTE & TESTE \\
\hline $\begin{array}{l}3 \text { objetos inventados de cores diferentes, } \\
\text { com a mesma forma e com a mesma } \\
\text { propriedade } \\
\text { (ex. triângulos verdes) }\end{array}$ & $\begin{array}{l}\text { Distratores } \\
\text { a) } 2 \text { objetos conhecidos s/ a } \\
\text { propriedade-alvo (ex. bola e flor); } \\
\text { b) } 1 \text { objeto inventado semelhante } \\
\text { ao da fase de Familiarização, sem a } \\
\text { propriedade-alvo; } \\
\text { c) } 1 \text { objeto inventado diferente do } \\
\text { da fase de Familiarização, sem a } \\
\text { propriedade-alvo; }\end{array}$ & $\begin{array}{l}\text { Objeto inventado igual ao da } \\
\text { Familiarização, de outra cor, } \\
\text { com outra propriedade (ex. com } \\
\text { quadrados laranja) } \\
\text { X } \\
\text { Objeto inventado igual ao do } \\
\text { Contraste, de outra cor, com } \\
\text { a propriedade-alvo (ex. com } \\
\text { triângulos verdes) }\end{array}$ \\
\hline & $\begin{array}{l}\text { Alvo } \\
\text { Objeto inventado com a propriedade- } \\
\text { alvo (ex. com triângulos verdes) }\end{array}$ & \\
\hline
\end{tabular}

Quadro 1 - Conjunto 1 de objetos

Resultados e discussão:

Os dados deste experimento foram analisados considerando-se o número de escolhas referentes aos objetos inventados que apresentavam a propriedade-alvo, ou seja, a mesma propriedade dos objetos da fase de familiarização. O gráfico abaixo apresenta a distribuição de respostas-alvo em função da posição estrutural do adjetivo e da presença/ausência de sufixo.

\section{Gráfico 1}

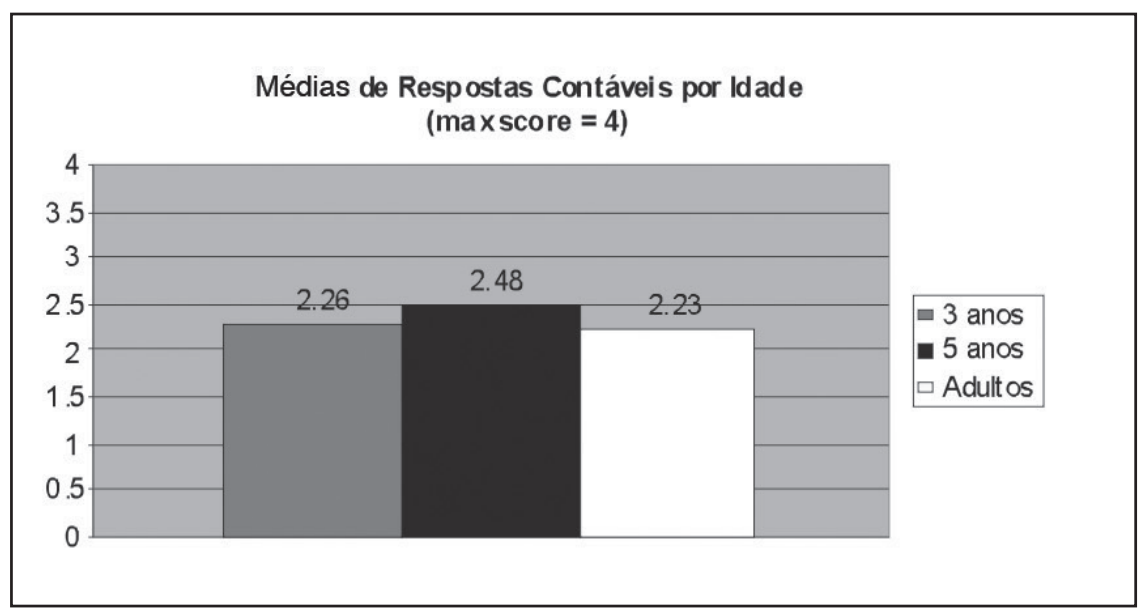

Por meio da análise da variância (two-way ANOVA), temse que os resultados indicam um efeito principal da ordem nome/adjetivo, com mais respostas concernentes à propriedadealvo dos objetos nas condições experimentais em que o adjetivo aparece à direita do nome do que naquelas em que ele aparece à esquerda do nome: $F(1,15)=36.15, p<.00001$. No que tange à presença/ausência de afixos, os resultados também apontam 
um efeito principal da presença de afixo, com mais respostas relativas a propriedades dos objetos nas condições com afixos derivacionais: $\mathrm{F}(1,15)=10.38, \mathrm{p}<.01$. Houve interação significativa entre as variáveis: $\mathrm{F}(1,15)=24.77, \mathrm{p}<.001$.

Portanto, o efeito principal das variáveis independentes e o da interação entre as variáveis manipuladas sugerem que as crianças fixam, desde muito cedo, os valores dos parâmetros relativos à ordem das palavras (p. ex. Det $+\mathrm{N}+$ Adj), percebendo na fala à sua volta determinados "padrões recorrentes" de natureza sintática (como o fato de que algumas palavras tendem a ser precedidas, com frequência, por outras de classes fechadas (p. ex. Det + Nome) e de natureza morfológica (como a presença de afixos derivacionais após as raízes lexicais, no caso deste experimento). Na presença do sufixo derivacional, a informação morfofonológica é prevalente para o estabelecimento pela criança da correspondência entre a pseudopalavra com sufixo e a propriedade (=adjetivo), principalmente nas condições experimentais em que o adjetivo aparece à esquerda do nome, ou seja, na posição não-canônica (Det + Adj + N). Tais informações são levadas em conta pela criança na delimitação da categoria lexical correspondente a adjetivos, distinguindo-os de nomes. Os resultados indicam que adjunção de adjetivos no DP contribui para a interpretação da referência específica, chamando a atenção da criança para uma propriedade do elemento referido.

Contudo, o que não está bem claro é em que medida os traços semânticos dos afixos formadores de adjetivos são representados pela criança, isto é, em que medida ela é capaz de interpretar esses traços na interface semântica. A seguir, apresenta-se um segundo experimento com crianças, em que se focaliza sua capacidade em atribuir significado às propriedades expressas por pseudoadjetivos, tomando como pista os afixos derivacionais -oso e -ento associados às raízes lexicais dessas pseudopalavras.

\subsection{Experimento 2 - Sensibilidade por parte de crianças à informação semântica dos afixos derivacionais -oso e -ento, formadores de adjetivos denominais}

\footnotetext{
${ }^{4} \mathrm{Na}$ confecção dos materiais utilizados no pré-teste, procurou-se estabelecer a seguinte associação: aos objetos com florezinhas ou coraçõezinhos deveria corresponder uma propriedade positiva; aos objetos com farrapos e buracos deveria corresponder uma propriedade negativa. Para se ter exemplos, ver Fig. 2.
}

\subsubsection{Pré-teste}

Para a realização do Experimento 2, foi elaborado, em primeiro lugar, um pré-teste com vistas a verificar se, diante de dois objetos, um com uma propriedade supostamente positiva e outro com propriedade supostamente negativa ${ }^{4}$, a criança tinha preferência por um ou por outro. O pré-teste foi conduzido com 12 crianças (6 de cada grupo etário), contrabalançadas em dois grupos em função da idade e do tipo de objeto a que foram apresentadas - com o traço [+animado] ou [-animado]: 
a) grupo I (Inanimado): 3 crianças entre $2-3$ anos; 3 crianças entre 4-5 anos;

b) grupo A (Animado): 3 crianças entre $2-3$ anos; 3 crianças entre $4-5$ anos.

Os dados do grupo Inanimado e os do grupo Animado, em ambas as faixas etárias, foram inicialmente comparados e, dada a semelhança das médias obtidas, não houve indício de que animacidade e idade pudessem ser variáveis relevantes nas escolhas das crianças. Assim sendo, por meio de um Teste Binomial, procurou-se verificar se houve preferência por um dos objetos apresentados, em função do tipo de propriedade contrastada. Os resultados indicaram uma tendência para a escolha do objeto com propriedade de valor positivo, ainda que a preferência por este não tenha alcançado o nível de significância: $\mathrm{z}$ ( 2 tailed $)=1.88$; $\mathrm{p}=.06$. Isso sugere que as crianças avaliam os objetos de forma semelhante à pretendida na caracterização das propriedades dos mesmos, embora essa avaliação não as leve a rejeitar os objetos com propriedades tidas como negativas em suas escolhas. Diante disso, considerou-se que a escolha de objetos com propriedades consideradas positivas ou negativas no pré-teste poderia ocorrer em função da interpretação semântica dos afixos. Isso posto, apresenta-se a seguir o experimento propriamente dito, em que se ampliou o número de participantes por faixa etária, com vistas a verificar o efeito do tipo de afixo diante da tendência acima referida.

\subsubsection{Experimento 2}

\section{Objetivos:}

(i) obter evidências sobre o conhecimento de crianças brasileiras de 2-3 anos e 4-5 anos, relativo à informação de natureza semântica dos sufixos derivacionais -oso e -ento, formadores de adjetivos;

(ii) verificar se os fatore "idade" e "animacidade" interferem na interpretação semântica do afixo por parte das crianças.

Variáveis Independentes (compondo um design 2X2):

a) Congruência entre o significado atribuído ao afixo (-oso/-ento) e à propriedade do objeto (supostamente positiva ou negativa):

(i) congruente: a propriedade física do objeto (com florezinhas/ coraçõezinhos ou furos/farrapos) corresponde ao valor (positivo ou negativo) associado ao sufixo; 
(ii) incongruente: a propriedade física do objeto (com florezinhas/ coraçõezinhos ou furos/farrapos) não corresponde ao valor (positivo ou negativo) associado ao sufixo.

b) Animacidade: animado / inanimado (fator grupal);

c) Idade (fator grupal).

Variável dependente: número de escolhas compatíveis com o significado do sufixo empregado na familiarização.

Hipótese:

A criança interpreta os sufixos -oso/-ento como indicativos de propriedades positivas/negativas, respectivamente.

Condições experimentais:

Condição 1: congruente c/ -oso

Condição 2: congruente c/ -ento

Condição 3: incogruente c/ -oso

Condição 4: incogruente c/ -ento

\section{Previsões:}

Se a criança for sensível à informação semântica dos afixos derivacionais formadores de adjetivos com -oso/-ento, associando valor positivo/negativo, respectivamente, às propriedades dos nomes modificados por esses pseudoadjetivos, então:

(i) o afixo -oso favorece avaliação positiva. Espera-se um efeito de tipo de afixo com maior número de respostas para o pseudoadjetivo interpretado como indicativo de uma avaliação positiva na "condição -oso";

(ii) o afixo -ento favorece avaliação negativa. Espera-se um efeito de tipo de afixo, com maior número de respostas para o pseudoadjetivo interpretado como indicativo de uma avaliação negativa na "condição -ento".

Preparação dos estímulos:

Foram elaboradas 8 listas em que a ordem das condições experimentais foi aleatorizada, de modo a garantir que uma mesma condição não se repetisse sucessivamente. Um mesmo pseudoradical foi empregado, uma única vez, em cada condição experimental. Por exemplo: (i) mip \{-oso\} congruente; (ii) mip \{-ento\} congruente; (iii) mip \{-oso\} incongruente; (iv) mip \{-ento\} incogruente. Cada criança foi apresentada a um radical uma vez. Os pseudoadjetivos utilizados nas sentenças durante a realização das tarefas foram os seguintes: lufoso/lufento; daboso/dabento; 
tafoso/tafento; riboso/ribento; maboso/mabento; toboso/tobento. Para uma melhor compreensão acerca da condução deste experimento, ver a subseção referente ao procedimento adotado.

\section{Método:}

Participantes: As tarefas experimentais foram aplicadas inicialmente a 46 crianças de duas escolas, ambas em Juiz de Fora, mas realizadas em todas as instâncias por 38: 18 de 2-3 anos (8 do sexo masculino e 10 do feminino) e 20 de $4-5$ anos (igualmente divididas entre os dois sexos). Cada grupo etário foi dividido da seguinte forma:

a) Grupo 1 (Animado): 10 crianças de 2-3 anos e outras 10 de 4-5 anos;

b) Grupo 2 (Inanimado): 8 crianças de 2-3 anos e outras 10 de 4-5 anos.

\section{Materiais:}

Foram utilizados os objetos manufaturados do pré-teste (ver Fig. 2 a seguir) e estes foram divididos em dois grupos: um primeiro grupo de objetos com o traço [-animado], e um segundo grupo de objetos com o traço [+animado], ambos contendo as mesmas propriedades, a saber: com florezinhas ou coraçõezinhos (propriedades supostamente positivas), com farrapos ou furos (propriedades supostamente negativas). Objetos sem propriedade saliente (lisos) foram considerados neutros.

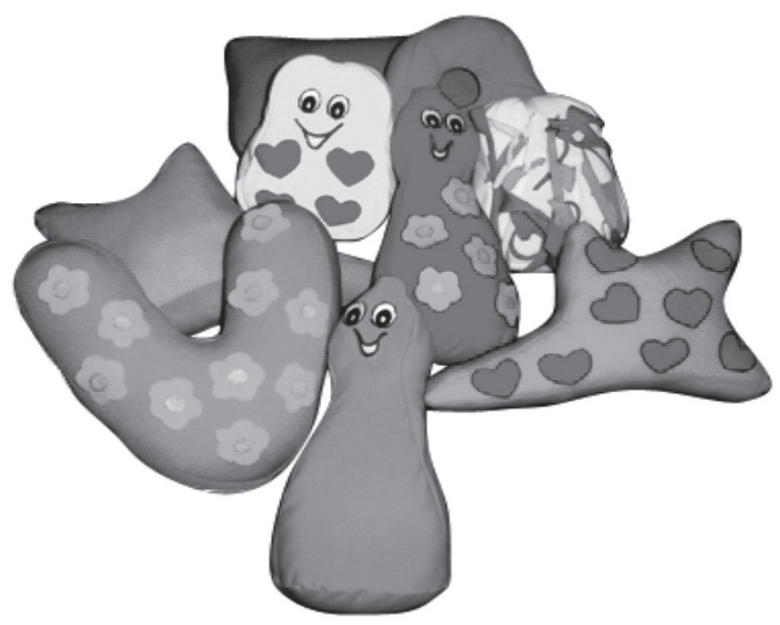

Fig. 2 - Objetos manufaturados

Procedimento:

A criança teve como tarefa selecionar um dentre dois objetos, contendo uma propriedade determinada, à qual o pseudoadjetivo, dependendo da condição experimental, deveria se referir. Cada 
criança foi submetida a quatro condições experimentais duas vezes, sendo que a ordem de apresentação das condições por criança foi aleatorizada. O procedimento incluiu familiarização, contraste e teste, sendo que as escolhas dos participantes foram anotadas para análise posterior. Exemplos de sentenças com pseudoadjetivos, distribuídos em função da condição experimental em cada fase, estão transcritos a seguir:

\section{Condição 1: congruente c/ -oso}

Familiarização (Congruente): "objetos -oso" $\rightarrow$ com florezinhas

"Este aqui é miposo. Este aqui também é miposo. E este outro aqui é miposo também".

Contraste: outro objeto da mesma categoria com propriedade pejorativa (com farrapos) e um objeto diferente sem propriedade (neutro).

"Ih, este aqui não é miposo!". "Este outro aqui também não é miposo ".

Teste: objeto da mesma categoria do da fase de familiarização com propriedade pejorativa (com farrapos) $\mathrm{X}$ um objeto diferente com a mesma propriedade dos objetos da familiarização com o afixo -oso (com florezinhas).

"Pega o miposo pra mim."

\section{Condição 2: congruente c/ - ento}

Familiarização (Congruente): objetos -ento $\rightarrow$ com furos

"Este aqui é lufento. Este aqui também é lufento. E este outro aqui é lufento também".

Contraste: outro objeto da mesma categoria com propriedade positiva (com corações) e um objeto diferente sem propriedade (neutro).

“Ih, este aqui não é lufento!”. “Este outro aqui também não é lufento ".

Teste: objeto da mesma categoria do da fase de familiarização com propriedade positiva (com corações) X um objeto diferente com a mesma propriedade dos objetos da familiarização com o afixo -ento (com furos).

"Pega o lufento pra mim." 


\section{Condição 3: incogruente c/-oso}

Familiarização (Incongruente): objetos com propriedade pejorativa $\rightarrow$ com furos

"Este aqui é daboso. Este aqui também é daboso. E este outro aqui é daboso também".

Contraste: outro objeto da mesma categoria com propriedade positiva (com florezinhas) e um objeto diferente sem propriedade (neutro).

"Ih, este aqui não é daboso!”. “Este outro aqui também não é daboso".

Teste: objeto da mesma categoria do da fase de familiarização com propriedade positiva (com florezinhas) X um objeto diferente com a mesma propriedade pejorativa dos objetos da familiarização com o afixo -oso (-oso incongruente $=$ objeto com furos).

"Pega o daboso pra mim."

\section{Condição 4: incogruente c/ - ento}

Familiarização (Incongruente): objetos com propriedade positiva $\rightarrow$ com coração

"Este aqui é tafento. Este aqui também é tafento. E este outro aqui é tafento também".

Contraste: outro objeto da mesma categoria com propriedade pejorativa (com farrapos) e um objeto diferente sem propriedade (neutro).

“Ih, este aqui não é tafento!". “Este outro aqui também não é tafento ".

Teste: objeto da mesma categoria do da fase de familiarização com propriedade pejorativa (com farrapos) X um objeto diferente com a mesma propriedade positiva dos objetos da familiarização com -ento (-ento incongruente = com coração) $\rightarrow$ "Pega o tafento pra mim."

Resultados e discussão:

Para o tratamento dos dados, foi considerado o número de escolhas compatíveis com o significado do sufixo que foi associado à propriedade-alvo dos objetos na fase de familiarização. 
Gráfico 2

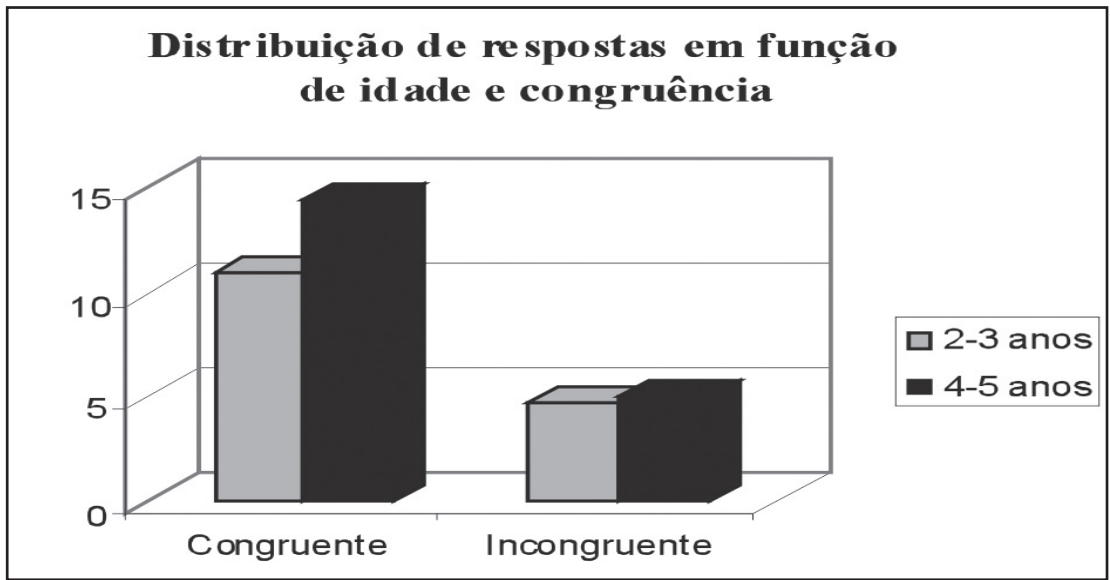

Houve um efeito principal da variável idade: $\mathrm{F}(1,34)=14,3$, $\mathrm{p}<.001$, com mais respostas relativas à congruência do significado dos afixos no grupo de crianças mais velhas, independentemente das propriedades do objeto de escolha: se positivas ou negativas (Médias: 2 anos= 1.93; 4 anos=2.17). $O$ efeito de animacidade não foi significativo. $\mathrm{O}$ gráfico 3 abaixo apresenta as médias obtidas em função de congruência e tipo de afixo nos dois grupos etários, tomados em conjunto.

\section{Gráfico 3}

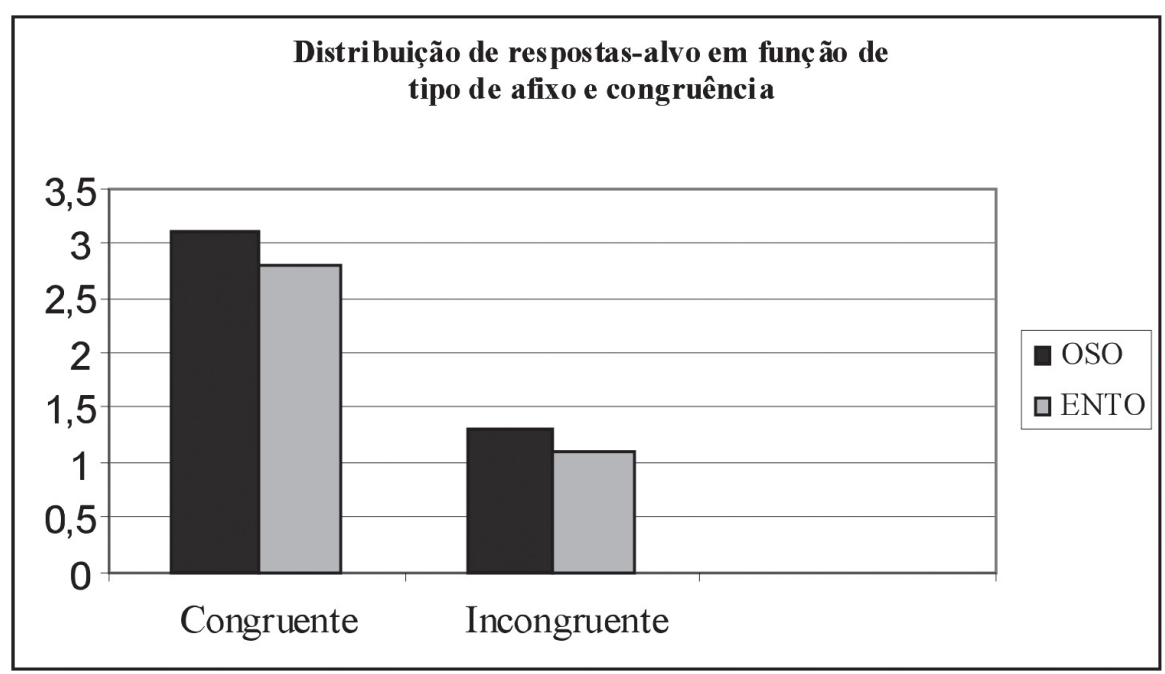

O efeito de tipo de afixo foi significativo: $\mathrm{F}(1,34)=9,7, \mathrm{p}<.01$ (Médias: -oso $=2.21$; -ento $=1.92$ ), assim como o de congruência: $\mathrm{F}(1,34)=61,7, \mathrm{p}<.001$, com maior número de respostas com valor positivo na condição congruente com o sufixo -oso e maior número de respostas negativas na condição congruente com o sufixo -ento (Médias: congruente= 2.92; incongruente=1.21). Não houve interação significativa entre esses fatores assim como desses fatores com 
idade, o que indica que os resultados do efeito de congruência se aplicam independentemente do tipo de afixo e da idade.

Os resultados obtidos são compatíveis com a hipótese de que a criança é sensível à informação semântica dos afixos derivacionais -oso/-ento, formadores de adjetivos denominais, associando valor positivo/negativo, respectivamente, às propriedades dos nomes modificados pelos adjetivos com tais afixos. Essa sensibilidade pode ser captada desde muito cedo (2-3 anos). Nota-se, contudo, pelo efeito principal de idade, que o número de respostas compatível com o adjetivo como atribuidor de propriedade, independentemente de seu valor positivo/negativo, aumenta entre as crianças mais velhas. Cumpre ressaltar que, se as crianças distinguem entre palavras novas apresentadas como nomes contáveis vs propriedades, e esta distinção é recrutada no aprendizado de palavras, isso implicará padrões de comportamento distintos nas condições congruente e incongruente. $\mathrm{Ou}$ seja, na condição incongruente, a criança parece optar pelo objeto familiar, mesmo que ele se mostre com uma nova propriedade. Já na condição congruente, a criança parece optar pelo objeto que traz a propriedade já familiar, mesmo que esta seja apresentada em um novo objeto.

\section{Considerações finais}

Partindo do pressuposto de que aquilo que é sistemático na língua é tomado pela criança como índice de informação gramaticalmente relevante para dar início ao processamento de enunciados linguísticos, o primeiro experimento buscou investigar o papel dos elementos de classe fechada (mais especificamente, determinantes e sufixos derivacionais), assumindo-se a sua sistematicidade como desencadeadores dessa análise. No que se refere à interpretação semântica dos sufixos, as evidências experimentais indicam que a criança parece ser capaz de mapear diferentes propriedades (intuitivamente positivas ou negativas, por ex., tendo em vista os sufixos -oso e-ento, respectivamente), atribuindo-as a uma determinada categoria, e estendendo-as a uma outra. No caso do Experimento 2, os resultados indicam que já por volta do segundo ano de vida, as crianças são capazes de identificar os sufixos na interface fônica e interpretá-los na interface semântica (ainda que essa habilidade aumente dos 4 para os 5 anos). As crianças delimitam uma forma gramatical (enquanto elemento do léxico que atribui propriedades a um elemento nomeado) identificada como adjetivo, dado o pressuposto de que enunciados linguísticos se referem a entidades e eventos. Com este estudo, procurou-se contribuir para uma teoria da aquisição da linguagem fundada no processamento de informação das interfaces da língua com sistemas perceptuais e conceptuais, na qual se enfatiza o papel de categorias funcionais e de elementos de classe fechada, tais como 
os sufixos derivacionais, na identificação do que há de específico na língua.

\begin{abstract}
This paper presents an experimental study of the delimitation of adjectives as a lexical category in the acquisition of Brazilian Portuguese. It reconciles a psycholinguistic approach to language acquisition with a minimalist conception of language (CHOMSKY, 1995-2001). According to the phonological bootstrapping hypothesis (MORGAN \& DEMUTH, 1996; CHRISTOPHE et al., 1997), it is assumed that infants are sensitive to closed class elements (as determiners and affixes) in the processing of the phonetic interface. According to the syntactic bootstrapping hypothesis (GLEITMAN, 1990), it is assumed that the parsing of adjectives in DP and small clause contexts, together with the assumption that DPs refer to objects/ entities, allow the representation of the adjectives as words that present a property or an attribute of a given referent. And the role of the canonical word order in the distinction between nouns and adjectives is evaluated. Two experiments are presented: both of them were conducted with children, making use of the object selection with pseudo-words paradigm. The first experiment was conducted with 18-22 month old children, and the second one, with 2-3 and 4-5 year olds. The results of the experiments reported here are compatible with the hypothesis that children make use of syntactic and morphological information in the delimitation of adjectives as a lexical category. They also reveal that the semantic properties of derivation affixes forming adjectives are already available by the age of two.
\end{abstract}

Keywords: language acquisition; adjective; bootstrapping; lexical categories; functional categories; derivational affixes 


\section{REFERENCIAS}

ALMEIDA, C. P. de. A identificação de nomes e adjetivos por crianças adquirindo o PB. Dissertação (Mestrado em Letras), Universidade Federal de Juiz de Fora, 2007

CHOMSKY, N. Beyond Explanatory Adequacy. MIT Occasional Papers in Linguistic, v.20, 2001

1999 _. Derivation By Phase. MIT Working Papers in Linguistics,
Press, 1995

The Minimalist Program. Cambridge, Mass: The MIT

CHRISTOPHE, A. et al. Reflections on Phonological Bootstrapping: its role for lexical and syntactic acquisition. Language and Cognitive Processes, vol. 12, n. 5/6, p. 585-612, 1997

CORREA, L. M. S. Conciliando processamento linguístico e teoria de língua no estudo da aquisição da linguagem: habilidades discriminatórias de bebês, categorias funcionais e a disponibilidade de um sistema computacional linguístico. In : Corrêa, L.M.S. (org.). Aquisição da Linguagem e Problemas do Desenvolvimento Linguístico. Rio de Janeiro: Editora da PUC-RJ, p. 21-78, 2006

GLEITMAN, L. The structural sources of verb meanings. Language Acquisition, v.1, p.3-55, 1990

MINTZ, T. H. \& GLEITMAN, L. Adjectives really do modify nouns: the incremental and restricted nature of early adjective acquisition. Cognition, 84 (3), p. 267-293, 2002

MORGAN, J. L.; DEMUTH, K. Signal to Syntax: an overview. In: J. L. Morgan \& K. Demuth (Orgs.). Signal to Syntax: Bootstrapping from speech to grammar in early acquisition. Mahwah, New Jersey: Lawrence Erlbaum Associates, p. 1-22, 1996

NAME, M. C. L. Aquisição de nomes e adjetivos por crianças brasileiras: uma abordagem psicolinguística. Revista Estudos Linguísticos, Campinas, v. XXXIV, p. 415-420, 2005

ROSA, M. C. Introdução à morfologia. São Paulo: Contexto, 2000

TEIXEIRA, E. R. A adaptação dos Inventários MacArthur de Desenvolvimento Comunicativo (CDI's) para o português brasileiro. In: Anais do II Congresso Nacional da ABRALIN. Taciro - Produção de CDs Multimídia. 479 - 487, 2000

. Specifying the scope of 13-month-olds' expectations for novel words. Cognition, 70, B35-B50, 1999

WAXMAN, S. R. \& BOOTH, E. Seeing pink elephants: Fourteenmonth-olds' interpretations of novel nouns and adjectives. Cognitive Psycology, 43, 217-242, 2001 